\title{
ОБОСНОВАНИЕ МАКСИМАЛЬНОЙ ДОПУСТИМОЙ СКОРОСТИ ВОЗДУХА В СТВОЛАХ ПО ФАКТОРУ АЭРОДИНАМИЧЕСКОЙ НАГРУЗКИ НА ТЕХНОЛОГИЧЕСКОЕ ОБОРУДОВАНИЕ
}

\author{
Д.А. Поспелов, А.В. Зайцев, М.А. Семин \\ Горный институт УрО РАН, г. Пермь
}

\begin{abstract}
Аннотация: Произведено многовариантное 3D моделирование динамики воздушных потоков в турбулентном режиме для скипового ствола рудника «Октябрьский» ПАО «ГМК «Норильский никель» при различных скоростях движения воздуха и месторасположениях подъемных сосудов. Полученные результаты нагрузок свидетельствуют о незначительном аэродинамическом влиянии воздушного потока на технологическое оборудование (движущийся скип и канат). Таким образом, при оценке допустимой скорости воздуха в скиповых стволах определяющими должны быть другие факторы, в частности, энергозатраты на проветривание ствола.

Ключевые слова: рудничная вентиляция, численное моделирование; максимальная скорость воздуха; шахтный ствол; технологическое оборудование.
\end{abstract}

\section{Введение}

С увеличением площадей отработанных участков и увеличением глубины ведения горных работ возникает необходимость повысить производительность главных вентиляторных установок на рудниках. Увеличить подачу воздуха в шахту можно задействовав нейтральные стволы, которыми как правило являются скиповые. Поскольку скиповые стволы оснащены в большей степени технологическим оборудованием возникает вопрос об аэродинамическом влиянии высокоскоростных потоков воздуха на это оборудование.

Согласно действующей на территории РФ нормативной литературе [1], в стволах, предназначенных только для спуска и подъема грузов, максимальная допустимая скорость воздуха может быть не более 12 м/с. В монографиях [2-3] авторов D. J. Brake, M. J. McPherson говорится о том, что при высоких скоростях воздуха в стволах с направляющими могут возникать следующие проблемы:

1. Вибрация подъемных сосудов, приводящая к поломкам и разрушениям.

2. Колебания в канатах.

3. Возможное столкновение подъемных сосудов в середине ствола с канатными направляющими.

4. Стук об расстрелы в месте, где проходят транспортные средства.

Аэродинамические нагрузки на технологическое оборудование в скиповых стволах определяются не только скоростью воздуха, но и скоростью движения подъемных сосудов [4]. В. Д. Белый считал, что сила Кориолиса во время движения транспорта в стволе в результате вращения Земли была основным источником возбуждения, которая вызывала боковые колебания, и он вывел формулу для расчета зазора между транспортными средствами [5]. Проведя натурные измерения в ряде шахт с помощью лазерного измерителя колебаний, Чен $[6,7]$ обнаружил, что смещения транспортных средств несовместимы с результатами расчета по формуле Белого [8], а сила Кориолиса оказала небольшое влияние на транспортные средства. В работах Бучински [9] проведен анализ траекторий движения скипов с использованием бортовой инерциальной навигационной системы (INS), а результаты показали, что величина горизонтального движения транспорта связана с остаточным несбалансированным крутящим моментом головы/хвоста троса, силой Кориолиса и скоростью подъема. Фактически, аэродинамическая сила, которая связана со скоростью подъема и вентиляцией, играет важную роль в горизонтальном движении канатных направляющих. 
Другие факторы, которые также следует учитывать при выборе скорости воздуха в скиповых стволах, приведены ниже:

1. Энергоэффективность непосредственно связана с увеличением скорости воздуха: чем выше скорость воздуха, тем больше энергозатраты $\left(N \sim Q^{3}\right)$, где $N$ - энергозатраты на поддержание расхода воздуха в стволе, $Q^{3}-$ расход воздуха [10].

2. Газ и пыль. Ограничение максимальной скорости вызвано тем, что при большом ее значении пыль и газ поднимается на воздух, способствуя тем самым образованиям взрывоопасных смесей (особенно на угольных шахтах) и концентраций. Так же если ствол является воздухоподающим, то этот фактор может привести к загрязнению свежей струи. [11].

3. Капеж в стволе. Наличие воды приводит к увеличению сопротивления, затрудняя проветривание.

4. Площадь «живого сечения» в стволе для потока воздуха. Стволы с меньшим количеством армировки, могут выдерживать более высокие скорости воздуха.

5. Скорость перемещения подъемных сосудов: чем выше скорость транспорта, тем ниже допустимая скорость воздуха в шахте.

6. Ветровая нагрузка на людей, находящихся в клети и регулярно работающих в стволе (персонал по обслуживанию). Высокие скорости воздуха создают предпосылки для простудных заболеваний [11], однако это не актуально для скиповых стволов.

7. Технологическое оборудование в стволе (подъемные сосуды, гибкая или жесткая армировка, ходовое отделение, различные трубные и кабельные оснащения), которое необходимо регулярно обслуживать. Учитывая трудности работы в стволе, а также возможность колебаний, вибраций, соударений оборудования, скорости воздуха должны быть ограничены и безопасны.

Влияние скорости воздуха на аэродинамические нагрузки технологического оборудования в стволе ранее не рассматривалось и не моделировалось, поэтому было принято решение произвести численное моделирование и рассчитать максимально допустимую скорость в скиповых стволах на примере СC-1 с имеющимся оборудованием.

\section{Выбор расчетного модуля}

На примере рудника «Октябрьский» увеличить подачу воздуха в рудник можно задействовав нейтральные скиповые стволы CС-1 и СС-2. Поскольку скиповые стволы CC-1 и СС-2 идентичны, в дальнейшем рассматривался только ствол СС-1. В программном комплексе Ansys построена 3D физическая модель участка скипового ствола CC-1 длиной 100 м с имеющейся гибкой армировкой, двумя подъемными сосудами, лестничным отделением. Основные исходные данные, принятые для построения модели представлены в таблице 1.

Для решения поставленных задач использовались вычислительные методы динамики жидкости и газа (CFD-методы) [12]. Численное моделирование течения воздуха в стволе проводилось модуле CFX в трехмерной постановке с учетом гипотезы о стационарности распределения всех параметров воздуха (скорости, давления и пр.). Также принималось, что течение воздуха повсеместно происходит в режиме развитой турбулентности. Для расчёта турбулентных характеристик воздушного потока используется модель турбулентности standard $\mathrm{k}-\varepsilon$ c масштабируемыми пристеночными функциями $[13,14]$.

3D моделирование произведено при различных скоростях движения воздуха и следующих расположениях сосудов:

1. Скипы находятся на одном уровне на прямом участке ствола.

2. Скипы сдвинуты относительно друг друга на прямом участке ствола.

3. Прохождение одного из скипов сопряжения вентиляционного канала со стволом. 
Таблица 1

Исходные данные для построения модели

\begin{tabular}{|c|c|}
\hline Название & 3начение \\
\hline Диаметр ствола, мм & 6500 \\
\hline Длина ствола, мм & 100000 \\
\hline Площадь сечения вентиляционного канала, м ${ }^{2}$ & 6,3 \\
\hline Габаритные размеры кузова скипа 2 СН11-2К в плане, ширина, мм & 1680 \\
\hline Габаритные размеры кузова скипа 2 СН11-2К в плане, длина, мм & 1740 \\
\hline Высота скипа 2 СН11-2К, мм & 10200 \\
\hline Масса скипа, кг & 19100 \\
\hline Расстояние между соседними расстрелами, мм & 10000 \\
\hline
\end{tabular}

Месторасположения выбраны исходя из возможности несимметричности и максимально возможных нагрузок на подъемные сосуды. Для каждого из трех вариантов расположения сосудов рассмотрены 4 значения скорости воздушного потока в стволе. В итоге рассмотрено 12 вариантов (см. таблицу 2). Расположение сосудов представлены на рис. 1. По каждому из вариантов в результате моделирования получены следующие расчетные данные: максимальные значения сил, действующих на технологическое оборудование в осях OX, OY, OZ и напряжения, возникающие на уравновешивающих канатах. Эти данные послужили основой для дальнейшей оценки допустимых скоростей воздуха в стволе по критерию аэродинамические нагрузки технологического оборудования.

Таблица 2

Варианты моделирования при различных скоростях движения воздуха и трех месторасположений подъемных сосудов

\begin{tabular}{|c|c|}
\hline Расположение подъемных сосудов & $\begin{array}{c}\text { № варианта в зависимости от скорости воз- } \\
\text { духа }\end{array}$ \\
\hline \multirow{4}{*}{$\begin{array}{c}\text { Скипы находятся на одном уровне } \\
\text { на прямом участке ствола }\end{array}$} & 1. при $\vartheta_{\text {в }}=1,5$ м/с \\
\hline & 2. при $\vartheta_{\mathrm{B}}=9 \mathrm{M} / \mathrm{c}$ \\
\hline & 3. при $\vartheta_{\mathrm{B}}=18 \mathrm{~m} / \mathrm{c}^{*}$ \\
\hline & 4. при $\vartheta_{\text {в+скип }}=33 \mathrm{~m} / \mathrm{c}^{*}$ \\
\hline \multirow{4}{*}{$\begin{array}{c}\text { Скипы сдвинуты относительно друг друга } \\
\text { на прямом участке ствола }\end{array}$} & 5. при $\vartheta_{\mathrm{B}}=1,5 \mathrm{M} / \mathrm{c}$ \\
\hline & 6. при $\vartheta_{\mathrm{B}}=9 \mathrm{M} / \mathrm{c}$ \\
\hline & 7. при $\vartheta_{\text {в }}=18$ м/с* \\
\hline & 8. при $\vartheta_{\text {в+скип }}=33 \mathrm{~m} / \mathrm{c}^{*}$ \\
\hline \multirow{4}{*}{$\begin{array}{c}\text { Прохождение одного из скипов сопряжения } \\
\text { вентиляционного канала со стволом }\end{array}$} & 9. при $\vartheta_{\mathrm{B}}=1,5 \mathrm{~m} / \mathrm{c}$ \\
\hline & 10. при $\vartheta_{\mathrm{B}}=9$ м/с \\
\hline & 11. при $\vartheta_{\mathrm{B}}=18$ м $/ \mathrm{c}^{*}$ \\
\hline & 12. при $\vartheta_{\text {в+скип }}=33 \mathrm{~m} / \mathrm{c}^{*}$ \\
\hline
\end{tabular}

*Примечание: 1) Для исследования рассмотрено сверхнормативное превышение скорости -18 м/c.

2) Скорость воздуха равная 33 м/с - относительная скорость движения воздуха и скипа навстречу друг другу. Принимается исходя из скорости движения воздуха в стволе 18 м/с и максимальной скорости движения скипа по конструктивным требованиям 15 м/с. 




a

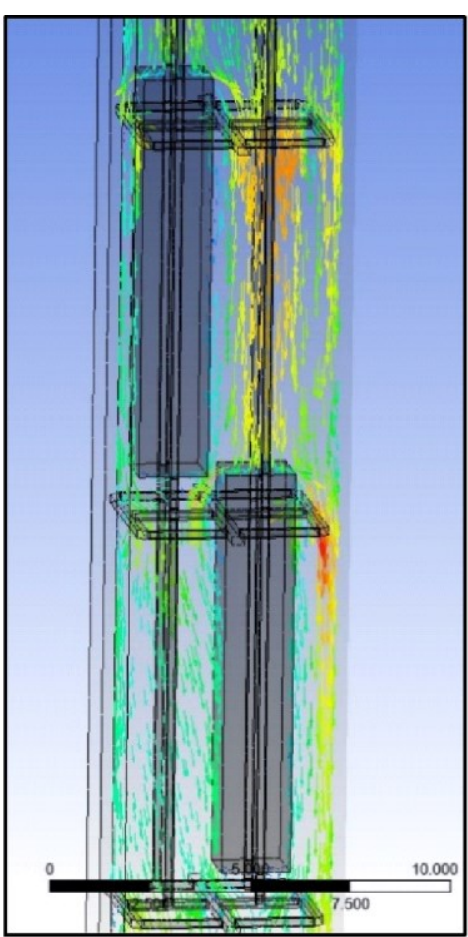

6

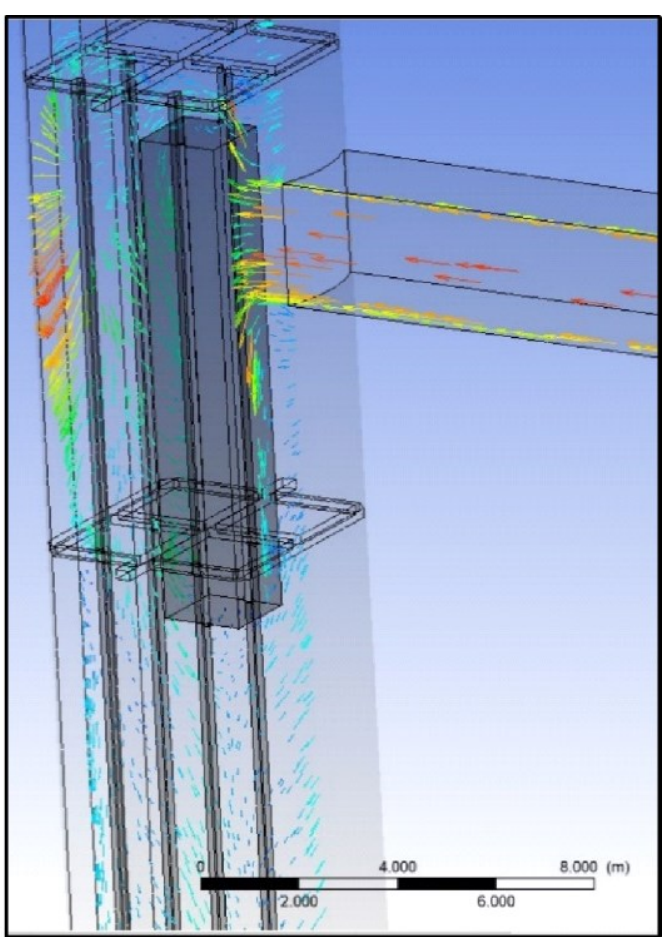

B

Рис. 1. Расположение подъемных сосудов: (а) - скипы находятся на одном уровне на прямом участке ствола, (б) - скипы сдвинуты относительно друг друга на прямом участке ствола, (в) - прохождение одного из скипов сопряжения вентиляционного канала со стволом

3D моделирование проводилось с двумя условиями задания типов стенок: гладкая и шероховатая. Результаты моделирования (перепады давления) при задании условий шероховатости стенкам крепи ствола, подъемным сосудам, армировки отличались на 15\% от результатов моделирования при гладком типе поверхности. Таким образом, шероховатостью стенок можно пренебречь, так как она не влияет на расчеты.

Из всех имеющихся вариантов будет рассмотрен вариант со скоростью воздуха 18 м/с при прохождении одного из скипов сопряжения вентиляционного канала со стволом, так как наблюдаются наибольшие нагрузки, способные привести к деформированию, колебаниям технологического оборудования.

Полученные параметры будут обозначены в следующем виде:

○ Максимальные значения сил, действующих на технологическое оборудование в осях OX, OY, OZ, H: $F_{\mathrm{OX}}^{\max }, F_{\mathrm{OY}}^{\max }, F_{\mathrm{OZ}}^{\max }$ соответственно;

○ максимальное растягивающее напряжение, действующее на канат с учетом веса скипа МПа- $\sigma_{\mathrm{p}}^{\max }$;

○ касательные напряжения, действующие на уравновешивающие канаты, Па $-\tau$;

○ нормальные напряжения, действующие на уравновешивающие канаты, Па $-\sigma$.

Расчетные параметры сил, действующих на подъемные сосуды в осях ОХ, OY сравнены с силой Кориолиса, действующей в горизонтальной плоскости и рассчитанной при максимальной скорости движения скипа по конструктивным требованиям 15 м/с. Нормальные и касательные напряжения, действующие на уравновешивающие канаты сравнены с растягивающими напряжениями в них. Результаты моделирования сведены в таблицу 3.

Сравнивая полученные значения аэродинамических сил, действующих на подъемный сосуд, с силой Кориолиса видно, что последняя на порядок выше по величине. Аналогичный вывод касается сравнения усилий, действующих на канат, - касательных напряжений, имеющих аэродинамическую природу, и нормальных напряжений вследствие веса скипа. Нагрузки на канат от аэродинамического сопротивления потока при 
его обтекании на много порядков ниже основной нагрузки на канат, обусловленной весом скипа и, следовательно, не могут быть причиной его существенных отклонений.

Таблица 3

Результаты моделирования при прохождении одного из скипов сопряжения вентиляционного канала со стволом при скорости движения воздуха 18 м/с

\begin{tabular}{|c|c|c|c|c|}
\hline $\boldsymbol{\vartheta}_{\mathrm{B}}=18 \mathrm{~m} / \mathrm{c}$ & Скип 2 & Расстрелы & Гибкая армировка & $\begin{array}{c}\text { Уравновешивающие } \\
\text { канаты }\end{array}$ \\
\hline$F_{\mathrm{OX}}^{\max }, \mathrm{H}$ & 21,85 & 3,3 & 3,84 & - \\
\hline$F_{\mathrm{OY}}^{\max }, \mathrm{H}$ & 14,66 & 3,81 & 3,87 & - \\
\hline$F_{\mathrm{OZ}}^{\max }, \mathrm{H}$ & 3,43 & 3,2 & 0,92 & 116,6 \\
\hline$\tau$, Па & - & - & - & 225,44 \\
\hline$\sigma$, Па & - & - & - & \\
\hline Сила Кориолиса $\left(F_{\mathrm{K}}\right), \mathrm{H}$ & & 41,8 & \\
\hline$\sigma_{\mathrm{p}}^{\text {max }}, \mathrm{MПа}$ & \multicolumn{5}{|c|}{} \\
\hline
\end{tabular}

Таким образом, при достаточно высокой скорости воздуха 18 м/с аэродинамическое влияние воздушного потока на скип и канат пренебрежимо малы по сравнению с другими факторами. Следовательно, при оценке допустимой скорости воздуха в скиповых стволах определяющими должны быть другие факторы, в частности, энергозатраты на проветривание ствола.

\section{БИБЛИОГРАФИЧЕСКИЙ СПИСОК}

1. Федеральные нормы и правила в области промышленной безопасности «Правила безопасности при ведении горных работ и переработке твердых полезных ископаемых». Вып. 78: утв. 11.12.2013, № 32935. - М.: 3АО НТЦ ПБ, 2016. - 276 с. - (Документы межотраслевого применения по вопросам промышленной безопасности и охраны недр: сер. 03). (с изменениями на 21 ноября 2018 г. в ред., действующей с 17 марта 2019 г.

2. Brake D. J., Mine Ventilation: A Practitioner's Manual. - Brisbane, Australia, 2013. - 791 p.

3. McPherson M.J. Subsurface ventilation and Environmental engineering. - London: Chapman \& Hall, 2009. - 935 p.

4. Wu R., Zhu Z., Cao G. Computational Fluid Dynamics Modeling of Rope-Guided Conveyances in Two Typical Kinds of Shaft Layouts // PLoS One. - 2015. - DOI: 10.1371/journal.pone.0118268.

5. Wu R., Zhu Z., Chen G., Cao G., Li W., Simulation of the lateral oscillation of rope-guided conveyance based on fluid-structure interaction // Journal of Vibroengineering, - 2014. - V. 16, № 3. - P. 1555-1563.

6. Chen X. Analysis of the Soviet calculation formula for the clearance between rope-guided conveyance and conveyance // Design of Coal Mine (China). - 1979. - V. 26, № 4 - P. 17-23.

7. Chen X. Swing of hoisting conveyance using steel rope guides // Coal Science and Technology (China). 1985. - V. 13, № 2. - Р. 23-26.

8. Белый В.Д. Канатные проводники шахтных подъемных установок. - М.: Углетехиздат, 1959. - 212 с.: ил.

9. Buchinski K.W. Skip rotation: a collision course or controllable motion: 11th CIM Underground Operators Conference. - Saskatoon, Canada, 1993.

10. Мохирев Н.Н. Проветривание рудников и шахт: Курс лекций для студентов горных специальностей ПГТУ. - Пермь, 1998. - 235 с.: ил.

11. Скочинский А.А., Комаров В.Б. Рудничная вентиляция: [Учебник для горных вузов]. - М.; Л.: Углетехиздат, 1949. - 444 с.: ил.

12. Качурин Н.М., Стась Г.В., Мохначук И.И., Поздеев А.А. Аэрогазодинамика очистных участков шахт и рудников // Проблемы безопасности и эффективности освоения георесурсов в современных условиях: материалы науч.-практ. конф., посвящ. 25-летию Горн. ин-та УрО РАН и 75-летию основателя и первого директора ин-та чл.-корр. РАН А.Е. Красноштейна / ГИ УрО РАН. - Пермь, 2014. - С. 381-386.

13. Hasheminasab F., Bagherpour R., Aminossadati S. M. Numerical simulation of methane distribution in development zones of underground coal mines equipped with auxiliary ventilation // Tunnelling and Underground Space Technology — 2019. — № 89. — P. 68-77.

14. Nel A. J.H., Vosloo J.C., Mathews M.J. Evaluating complex mine ventilation operational changes through simulations // Journal of Energy in Southern Africa - 2018. - № 29 (3). - P. 22-32. 